\title{
LA TRASCENDENCIA DEL LINAJE: LOS EMBAJADORES DE LA REPÚBLICA DE VENECIA EN MADRID DURANTE EL REINADO DE FELIPE IV (1621-1665)
}

\author{
David Quiles Albero* \\ Instituto Universitario "La Corte en Europa" \\ Universidad Autónoma de Madrid
}

\begin{abstract}
RESUMEN
En el presente ensayo pretendemos ahondar en el origen y carrera política de los embajadores venecianos en la corte española durante el reinado de Felipe IV, así como delimitar qué elementos fueron esenciales de cara a su elección como legados de la Serenissima. Con vistas a ello, es preciso señalar que, en lo tocante a los procesos electorales, la ley veneciana era sumamente estricta, buscando limitar la presencia de miembros de una misma casa en las distintas embajadas o mermar en las votaciones el peso de las relaciones no institucionales, las cuales eran consideradas corrupción. Antes bien, en las próximas páginas trataremos de poner de manifiesto la ineficacia de estos mecanismos a la hora de minimizar la influencia de los intereses personales y familiares de cara a la obtención de tan importantes cargos de representación.
\end{abstract}

PALABRAS CLAVE: Venecia, embajadores, Collegio, Senado, cursus honorum

*david.quiles@uam.es 


\title{
THE SIGNIFICANCE OF THE LINEAGE: VENETIAN AMBASSADORS IN MADRID DURING THE REIGN OF PHILIP IV (1621-1665)
}

\author{
David Quiles Albero* \\ Instituto Universitario "La Corte en Europa" \\ Universidad Autónoma de Madrid
}

\begin{abstract}
In this paper we will endeavor to inquire the origin and political career of the Venetian ambassadors in the Spanish court during the reign of Philip IV, as well as delimit the essential elements in the face of their election as legacies of the Serenissima. In view of this, it should be noted that, in regard to electoral processes, Venetian law was extremely stern: seeking to limit the presence of members of the same household in the different embassies or to reduce the prominence of non-institutional relations, whom were considered corruption. Notwithstanding, in the following pages we will try to highlight the ineffectiveness of these regulatory mechanisms to minimize the influence of personal and family interests in order to obtain such important representation positions.
\end{abstract}

KEYWORDS: Venice, ambassadors, Collegio, Senate, cursus honorum 
En las últimas décadas la nueva historia política y diplomática ha permitido ampliar el estudio de las relaciones entre las diferentes potencias durante la Edad Moderna ${ }^{1}$, utilizando para ello un enfoque socio-cultural con muchos más matices y posibles aproximaciones al rol que ejercieron los embajadores ${ }^{2}$.

Más todavía, no fue hasta mediados de los años ochenta que los individuos comenzaron a ganar una presencia significativa en los análisis históricos. Hasta entonces, los historiadores marxistas y de la escuela de Annales habían dado una importancia capital al estudio de las grandes estructuras a lo largo del tiempo; dejando a un lado a los sujetos históricos, más allá de la fascinación por los grandes personajes. Por todo ello, eran necesarios procedimientos y metodologías novedosos que pusieran de manifiesto una nueva forma de aproximarse a los hechos políticos y a sus protagonistas, con las que bajo ningún concepto se pretendía volver a la historia lineal o relato ${ }^{3}$.

$\mathrm{Al}$ respecto, es preciso señalar que este tipo de estudios -en los que los individuos de manera progresiva fueron cobrando un notable protagonismo a la hora de explicar la Historia- adquirieron especial relevancia tras la aparición del método prosopográfico; definido por L. Stone como el estudio colectivo de las vidas de un grupo de agentes históricos, con el fin de encontrar una serie de características comunes en todos ellos ${ }^{4}$. De este modo, se pretendía llevar a cabo un estudio de las estructuras administrativas desde un enfoque más bien sociológico, basándose en el análisis empírico y la cuantificación con miras a obtener una serie de conclusiones relevantes en lo tocante a las relaciones y redes clientelares establecidas entre estos individuos ${ }^{5}$.

En cuanto al patriciado veneciano, los estudios que han pretendido ahondar en esta corriente han tenido que lidiar con la tradicional exaltación del sistema político de la República de San Marcos. Hasta el punto de que, desde finales del siglo XIX, el mito de Venecia se ha ido convirtiendo en un

1. Este artículo ha sido posible gracias a la concesión de un contrato FPI-MINECO 2016 que se engloba dentro las ayudas a contratos predoctorales para la formación de doctores contemplada en el Subprograma Estatal de Formación, del Programa Estatal de Promoción del Talento y su Empleabilidad; en el marco del Plan Estatal de Investigación Científica e Innovación, 2013-2016, financiado con recursos procedentes del Fondo Social Europeo (FSE), dentro del proyecto HAR2016-68946-C3-1-P.

2. Un completo estado de la cuestión al respecto ha sido elaborado por D. CARRIÓ-INVERNIZZI (2013), 99-110; (2014), 603-618; (2016), 17-21.

3. F. Miranda Rubio (1994), 199-211.

4. L. Stone (1982), 61.

5. J. Martínez Millán (1996), 83-90. 
campo de estudio autónomo dentro de la historia véneta ${ }^{6}$. Lo mismo ocurre con sus embajadores, protagonistas de este ensayo, quienes despertaron el interés de la comunidad científica debido a esta proyección mítico-utópica y a la superioridad que les otorgaron los historiadores decimonónicos Müller o Ranke- por el simple hecho de haber sido los primeros en ser examinados junto a los nuncios apostólicos ${ }^{7}$.

Dicho lo cual, a la hora de ahondar en una "biografía colectiva" de los patricios venecianos, la cantidad de ensayos con que nos encontramos al respecto es inconmensurable en este artículo. No obstante, desde el punto de vista que aquí nos interesa, son especialmente significativos los trabajos de S. Andretta, V. Hunecke, D. E. Queller, D. Raines y F. de Vivo ${ }^{8}$; quienes han profundizado en aspectos capitales para el estudio de la oligarquía véneta como pueden ser su mitificación, las diferentes connotaciones del término familia, el cursus honorum, las redes de poder no institucionales, la lucha entre las diferentes facciones políticas o la progresiva aparición de la cultura de la meritocracia. Paralelamente, lo mismo sucede con los embajadores venecianos, ante la enorme admiración que a lo largo del tiempo ha despertado su aclamada diplomacia9.

Por todo ello, a todas luces resulta necesario plantear una serie de interrogantes a los que trataremos de dar respuesta en las siguientes páginas; tales como ¿quiénes fueron estos embajadores?, ¿qué relaciones de poder-formales e informales-fueron esenciales a la hora de ser promovidos a las principales embajadas? $\mathrm{y}$, finalmente, ¿qué papel jugaron estos individuos en la corte madrileña respecto a sus propios intereses y los de su República durante el reinado de Felipe IV?

\section{LA ELECCIÓN DE LOS EMBAJADORES EN LA REPÚBLICA DE VENECIA}

Los diplomáticos venecianos invariablemente formaban parte del patriciado y, en consecuencia, encarnaban la potestad de la oligarquía dominante, cuyos miembros eran inscritos desde el momento de su nacimiento en el

6. Vide G. Fasoli (1958b), vol. I, 445-479; F. Gaeta (1961), 58-75; E. Muir (1987), 13-61; M. P. Gilmore (1973), 431-444; E. O. G. Haitsma Mulier (1980); E. Crouzet-Pavan (1999).

7. D. E. Queller (1973), 177.

8. S. Andretta (2017), 176-196; V. Hunecke (1997); D. E. Queller (1986); D. Raines (1991), 827-847; (2003), 1-64; (2006), 279-317; (2016); F. DE VIVo (2007); (2012).

9. Entre otros, véase al respecto G. Volpi (1928); D. E. Queller (1966); (1967); C. CAMpana (2001), 43-58; J.-P. Pantalacci (2009), 263-277; A. Trampus (2010), 119-136; A. ZanNini (2010), 109-146; G. Alonge (2019). 
Libro d'Oro ${ }^{10}$. Del mismo modo, estos eran sancionados por sus pares en el Senado, máximo organismo legislativo de la Serenísima, que a lo largo del seiscientos llegó a estar compuesto por casi trescientos miembros ${ }^{11}$.

Así mismo, una de las grandes obsesiones de la República fue garantizar la transparencia de los procesos electorales, con el objetivo de asegurar una presencia homogénea de las veinticuatro grandes casas patricias en las principales magistraturas de gobierno ${ }^{12}$. Por todo ello, a la hora de elegir a sus legados, los familiares más cercanos de los nominados -hasta el segundo grado de parentesco- no podían participar en los procesos en que estos eran ratificados, con vistas a asegurar la imparcialidad de los electores ${ }^{13}$.

Esta prohibición hace necesaria una reflexión con respecto a qué connotaciones se dieron al término familia en suelo veneciano. En sentido amplio, la familia equivalía a la casa, y era por tanto la que daba la relevancia social al linaje, fundamentalmente a través de la construcción de un pasado común memorable; mientras que, en un sentido más reducido, esta se refiere exclusivamente al ramo, es decir, a los parientes de hasta un segundo grado de consanguineidad. Ahora bien, en el ámbito político y económico el ramo era el más determinante, ya que la solidaridad familiar era un factor concluyente de cara a iniciar una carrera política en la Venecia del seiscientos, a tenor de unos objetivos e intereses compartidos ${ }^{14}$.

Más aún, los méritos individuales (temperamento, ingenio, formación, etc.) también eran traídos a colación a la hora de asignar uno de estos importantes cargos de representación ${ }^{15}$. Dicho lo cual, es preciso señalar que en el momento de su elección los futuros legados debían contar con al menos treinta años de edad y, en la gran mayoría de los casos, eran los primogénitos de su familia y habían ocupado con anterioridad algún cargo político relevante. Normalmente en el Collegio, puesto que los jóvenes patricios podían acceder a este organismo a partir de los veinticinco años. Además, tal y como ha señalado F. de Vivo, esta institución, cuyos miembros (savi) eran elegidos para un ejercicio de seis meses, adquirió especial relevancia hasta convertirse en "the republic's mouthpiece"; siendo sus integrantes

10. C. Campana (2001), 45-46; P. Canali y L. Curti (1988), 137-146.

11. W. J. Bowsma (1968), 61; E. Besta (1899).

12. Tras la Serrata del Maggior Consilgio en 1297 se confirmó un grupo oligárquico cerrado, formado por las veinticuatro grandes familias: case vecchie, es decir, las doce fundacionales, y otras doce incorporadas posteriormente. G. RöScH (2000), 67-88.

13. Así se delimitó en el Maggior Consiglio en 1259. Vide D. E. Queller (1966), 40-41.

14. D. Raines (2003), 23-24.

15. D. RAINes (2016), vol. I, 240-242 y 256-258. 
los encargados de despachar con los embajadores extranjeros, recibir los dispacci de los agentes venecianos en las distintas cortes o establecer los temas a tratar en las sesiones del Pregadi ${ }^{16}$.

No obstante, caeríamos en un grave error de base al considerar que la vía diplomática quedaba reservada a los cittadini originari de menor edad, ya que la carrera política de los patricios venecianos a través de las cortes europeas, si optaban por ella, corría paralela a su ascenso dentro de las principales instituciones en la ciudad de los canales. Al mismo tiempo, cabe tener presente que dentro del cursus honorum veneciano la carrera del embajador comenzaba con el manejo de las sedes de menor relevancia en Turín o Ámsterdam; seguidamente, continuaba en las cortes de las grandes coronas en Madrid, París o Londres; y culminaba con las misiones en la Viena imperial y, en última instancia, en Roma ante el pontífice ${ }^{17}$.

Paralelamente, es necesario precisar que el haber ocupado uno de estos cargos de representación era vital para alcanzar las más altas magistraturas en el Palacio Ducal. Sin ir más lejos, muchos de los dogos habían ejercido previamente como embajadores. Por ende, no erramos al afirmar que los méritos que estos patricios fueron acumulando a lo largo de su carrera diplomática fueron fundamentales para llegar a los más altos estadios de poder, puesto que eran los que más profundamente conocían los avatares de la política europea. De ahí que, tras finalizar sus legaciones, contasen con un asiento ex officio en las filas del Senado ${ }^{18}$.

Por todos estos motivos, era poco común que un noble veneciano, si tenía cierta ambición política, se plantease renunciar a regentar una de estas embajadas. Solo en casos muy concretos, ante la falta de medios para costear su misión, estos eran eximidos del cargo. De manera análoga, cabe destacar que la República únicamente otorgaba a sus legados 200 ducados mensuales que, como veremos, a todas luces resultaban insuficientes para sufragar su permanencia en una corte extranjera. Por esta razón, en la gran mayoría de los casos estos oficios acabaron recayendo en las familias venecianas más acaudaladas con representación en el Senado, que eran las que podían costear tan dispendiosas magistraturas ${ }^{19}$. Así las cosas, cabe reconsiderar la

16. A. Da Mosto (1937), tomo I, 22-23; F. De Vivo (2007), 37-40, 71-73; G. Fasoli (1958a), 115.

17. Biblioteca Nazionale Marciana di Venezia (BMV), Cod. It. VII, fol. 129. Relación de Giannantonio Muazza a finales del siglo XVII, citada en D. RaInes (2016), vol. I, 274-275.

18. G. Fasoli (1958a), 111.

19. C. Diehl (1967), 230, 236-237. 
imagen desinteresada de la oligarquía veneciana, ya que si sus miembros aceptaron tan onerosos cargos de representación fue porque esperaban obtener algo a cambio. Más concretamente, el acceso a las magistraturas más elevadas dentro del cursus honorum veneciano: las de procurador de San Marcos y dogo de la República. De este modo, debemos desechar la idea utópica del servicio exclusivo del patriciado a los intereses de la Serenísima frente a los suyos propios, fruto de la campaña propagandística llevada a cabo con vistas a mitificar el sistema político veneciano y sus principales actores desde el siglo XVI ${ }^{20}$. De hecho, D. E. Queller sugiere que estos sujetos hicieron todo lo posible para renunciar a aquellos cargos que no les interesaban; resultando, según él, mucho más deseable el cargo de bailo en Constantinopla -por las implicaciones económicas que tenía- que las restantes misiones diplomáticas en las cortes europeas ${ }^{21}$.

Avanzando en nuestro razonamiento, una vez aceptado el puesto se entregaba al representante una commissione -instrucción sobre sus principales cometidos que era elaborada previamente a su nombramiento- y entre seis meses y un año después de su elección partía hacia su nuevo destino. Desde allí, los embajadores se comunicaban con el Senado a través de dispacci semanales, que constituyen la fuente primordial para conocer su devenir en las distintas cortes europeas. Unos meses más tarde, a tenor de la lentitud con que eran tomadas las decisiones en el Pregadi, estas misivas eran contestadas con una o varias instruzioni ${ }^{22}$.

Asimismo, los diplomáticos venecianos no podían permanecer en una misma misión por más de dos años. Aunque a la postre, debido a las trabas burocráticas que dilataban por varios meses la llegada de sus sucesores, la duración de sus servicios se acababa prolongando hasta los tres años ${ }^{23}$. Precisamente, con la limitación de sus mandatos se pretendía evitar la creación de lazos entre el embajador y la corte de arribada. Por este motivo, se les prohibía también recibir regalos a título personal o ser acompañados por sus esposas e hijos, ya que a estos se les consideraba fácilmente persuasibles ${ }^{24}$.

Tras su regreso a Venecia, los embajadores tenían un plazo muy breve de tiempo para librar sus famosas relazioni ${ }^{25}$. Estas fueron una fuente

20. E. Muir (1987), 13.

21. D. E. Queller (1966), 30-31.

22. J.-P. Pantalacci (2009), 263-277.

23. G. Volpi (1928), 43.

24. A. Trampus (2010), 122-124.

25. El Maggior Consiglio las hizo obligatorias el 23 de diciembre de 1268. En 1425 se estipuló que estas debían ser libradas por escrito. Mientras que a partir de 1524 aquellos 
vital para incrementar el conocimiento que en la República se tuvo de las restantes potencias europeas, así como una herramienta esencial para la formación de futuros agentes diplomáticos ${ }^{26}$. No obstante, pese a la relevancia que estas fuentes han tenido en la construcción de la historia europea posterior, hoy en día parece superada la mitificación de la que gozaron a partir de la historiografía nacionalista decimonónica. A la hora de justificar esta afirmación, debemos tener en cuenta que desde el siglo XVII la elaboración de estos textos toma un carácter rutinario, que no permite analizar en profundidad los aspectos más inmediatos de la política en las cortes europeas; solamente perceptibles a través del estudio pormenorizado de los sucesivos dispacci ${ }^{27}$.

\section{DE ALVISE CORNER A MARIN ZORZI: LOS EMBAJADORES DE LA SERENÍSIMA EN MADRID DURANTE EL REINADO DE FELIPE IV}

Una vez que hemos puesto en claro el proceso de elección de los legados venecianos durante la Edad Moderna, pasamos a abordar el caso particular de los enviados a la corte española durante el reinado de Felipe IV (1621-1665). Parece innegable que era esta una embajada crucial para los intereses de la República, con vistas a dilucidar la estrategia a seguir por los españoles en la península de los Apeninos. Asunto que había preocupado a la República de San Marcos desde tiempos de los Reyes Católicos, pero especialmente tras la constatación de las aspiraciones de Carlos V por alcanzar la Monarquía Universal ${ }^{28}$.

Tras la entronización de Felipe IV, tuvieron lugar en suelo italiano sonadas desavenencias que hicieron temer un enfrentamiento directo entre ambas potencias. Cabe puntualizar que estas fueron una consecuencia directa de la escalada de tensión vivida durante el reinado anterior; con acontecimientos que dificultaron el entendimiento entre Madrid y Venecia tales como la disputa por el Saluzzo entre Saboya y Francia, el Interdicto (1606-07), la lucha por el control de la Valtelina, la primera guerra del

que no las depositasen en la Cancillería Secreta 15 días después de haberlas expuesto serían castigados severamente. A. Ventura (1976), 11-12. Así mismo, las relazioni sobre la embajada en Madrid pueden consultarse en la recopilación de N. BAROzzI y G. BERChet (1856), Serie 1: Spagna, vol. I.

26. R. Descendre (2007), 245-250; M. Rivero Rodríguez (2000), 33-35.

27. G. Benzoni (1990), 45-58; E. D. Dursteler (2011), 233-238; F. De Vivo (2011), 25-59.

28. M. J. Levin (2005), 13-42; M. Á. de Bunes Ibarra (2001), 591-618. 
Monferrato (1613-17), los enfrentamientos en el Adriático (1617) o la famosa conjuración de Venecia (mayo de 1618) ${ }^{29}$.

Así las cosas, aunque la señoría véneta siempre procuró mantenerse al margen de los enfrentamientos intrínsecos a la guerra de los Treinta Años (1618-1648), la desconfianza hacia la estrategia de la casa de Austria en suelo italiano provocó su acercamiento estratégico a los monarcas galos desde finales del siglo XVI. Dicho en otras palabras, tal y como propuso F. Thiriet, su posición debe ser interpretada como de «neutralité vigilante», anteponiendo en todo momento sus propios intereses. Por ello, si bien apoyó a Francia en los enfrentamientos con la Monarquía Católica que tuvieron lugar en la península itálica -la crisis de la Valtelina (1626) y la guerra de sucesión en Mantua (1628-1631)-, a decir verdad no estaba interesada en las guerras entre las grandes potencias europeas ${ }^{30}$.

Sin embargo, frente a todo pronostico, la situación cambio tras el estallido en 1645 de la guerra de Candía, que enfrentó a los venecianos con el Imperio otomano tras el ataque de estos últimos a su más valiosa posesión en el Mediterráneo oriental. Más de setenta años después de Lepanto, la lucha contra los musulmanes volvía a ser el principal factor de connivencia entre españoles y venecianos. No podía ser de otra forma, ya que poco podía esperar el Senado de los franceses, cuyas relaciones con el Diván, pese a no ser tan boyantes como en tiempos de Francisco I, seguían siendo cordiales ${ }^{31}$.

A todo ello, cabe añadir que la paz de Westfalia (1648), que comenzaba a negociarse en aquellos momentos, puso de manifiesto el cambio de rumbo de la política europea; tras la constatación de que la Monarquía hispana ya no era la única a la que temer por los venecianos, a tenor del interés que tanto Richelieu como Mazarino mostraron en hacerse con el control de Italia. Más aún, en las negociaciones que tuvieron lugar en Münster y Osnabrück los representantes de la República de San Marcos se mostraron particularmente activos, con vistas a alcanzar un acuerdo y lograr el apoyo de las grandes potencias católicas en la que se trató de convertir en una nueva "causa común" de la Cristiandad contra la Sublime Puerta ${ }^{32}$.

29. G. Benzoni (1988), 155-178; S. Andretta (2008), vol. IV, 1075-1092; B. Maréchaux (2012), 91-120; R. GonzÁlez Cuerva (2012), 337-346.

30. F. THIRIET (1952), 111-112.

31. K. M. Setton (1991), 131-133; E. TÜrkÇELik (2015), 39-68.

32. S. Andretta (1978); G. Poumarède (2000), 369-382; M. Rivero Rodríguez (2018), 6178; F. Negredo del Cerro (2016), 314-337; D. Quiles Albero (2019), 176-195. Sobre esta idea, el I marqués de La Fuente, embajador hispano en Venecia cuando estalló el 
Al mismo tiempo, sus agentes diplomáticos en las restantes cortes europeas también jugaron un papel determinante. En la corte española, a la que limitaremos este escrito, conseguir el apoyo del Rey Católico -quien siempre se había autoproclamado paladín de la Cristiandad ${ }^{33}$ - se tornaba en la principal negociación encargada a los representantes de la Serenísima en las sucesivas commissioni. Junto a esta labor, obtener a través de las redes informales de poder noticias sensibles respecto a los conflictos que asolaban los territorios hispanos en aquellos años -guerras en Cataluña, Portugal, Países Bajos y revueltas en Nápoles o Sicilia- se tornaba en otra operación capital para los intereses venecianos ${ }^{34}$.

Volviendo al tema que nos ocupa, al hablar de estos legados cabe retomar el enfoque prosopográfico con el que iniciábamos este escrito. Para incidir en él, enfocaremos la carrera de estos patricios en tres etapas distintas de su vida: magistraturas previas a sus misiones diplomáticas, embajadas regentadas y oficios posteriores hasta su muerte (Tabla 1). Seguidamente, ahondaremos en los casos más significativos en cada una de estas fases de la carrera política en la Venecia del siglo XVII.

conflicto, señalaba que los venecianos no descubrían "otra forma de poder subsistir con esperanza de reparar la invasión del turco si ajustándose entre sí las coronas no quedasen libres para poder cooperar con todas sus fuerzas en la causa común". Archivo General de Simancas (AGS), Estado, leg. 3545, fol. 13. Carta del marqués de La Fuente, 4 de noviembre de 1645. En estas mismas líneas se expresaba el legado veneciano en Madrid cuando estalló la guerra. Archivio di Stato di Venezia (ASV), Senato, Dispacci, Spagna, filza 80, fol. 64. Carta de Girolamo Giustinan al Senado, 23 de agosto de 1645. 33. M. a J. Rodríguez Salgado (2004), 22-24; L. Bély (2009), 7.

34. P. Preto (1994), 39-94; S. Andretta (2000), 71-76; (2010), 193-211; J. Petitjean (2013), 8-9. 
Tabla 1. Cursus honorum seguido por los embajadores venecianos en Madrid durante el reinado de Felipe $\mathbf{I V}^{35}$

\begin{tabular}{|c|c|c|c|}
\hline Embajador & Cargos previos & Embajadas & Promoción posterior \\
\hline $\begin{array}{c}\text { Alvise } \\
\text { Corner } \\
(1621-24)\end{array}$ & Savio agli ordini & Madrid & $\begin{array}{l}\text { Savio agli ordini y di } \\
\text { Terraferma; provv. sopra } \\
\text { le Galee, alle Artiglierie, } i \\
\text { Beni incuti y l'Esazione del } \\
\text { denaro pubblico; capi del } \\
\text { sest. di Dorsoduro; conser- } \\
\text { vatore alle Leggi; regolato- } \\
\text { re sopra la Scrittura }\end{array}$ \\
\hline $\begin{array}{l}\text { Leonardo Moro } \\
\quad(1624-27)\end{array}$ & $\begin{array}{c}\text { Savio agli ordini y di } \\
\text { Terraferma; provvedito- } \\
\text { re sopra i Conti y alle } \\
\text { Pompe; senador, miem- } \\
\text { bro del Pien Collegio, } \\
\text { capitán de Bérgamo; } \\
\text { sindaco, avogadore e } \\
\text { inquisitore di Terra- } \\
\text { ferma }\end{array}$ & Madrid & -------- \\
\hline $\begin{array}{c}\text { Alvise } \\
\text { Mocenigo } \\
(1627-31)\end{array}$ & $\begin{array}{l}\text { Savio agli ordini, po- } \\
\text { destá y capitán de Fel- } \\
\text { tre, commissario sopra } \\
\text { i viveri delle milizie in } \\
\text { Terraferma }\end{array}$ & Madrid & Arzobispo de Candía \\
\hline
\end{tabular}

35. A la hora de realizar esta tabla, que sintetiza las diferentes magistraturas que fueron desempeñando sucesivamente los embajadores venecianos en Madrid, hemos utilizado como fuentes primordiales los datos emanados del Dizionario Biografico degli Italiani, pero también los recogidos en fuentes como las relazioni de dichos legados [N. BAROzzI y G. Berchet (1856), Serie 1, vol. I], sus dispacci [ASV, Senato, Dispacci, Spagna, filze 52-102] y la completa relación de las casas venecianas recogida en el Campidoglio Veneto, in cui si hanno l'armi, l'origine, la serie de gl'huomini illustri et gli Albori della Maggior parte delle Famiglie, cosi estinte, come viventi, tanto cittadine quanto forastiere, che hanno goduto e che godono della Nobiltà Patritia di Venetia, elaborado por Girolamo Alessandro CAPELlari Vivaro en 1741, 4 vols., y custodiado en la BMV, Cod. It. VII, 18. 


\begin{tabular}{|c|c|c|c|}
\hline Embajador & Cargos previos & Embajadas & Promoción posterior \\
\hline $\begin{array}{l}\text { Francesco } \\
\text { Corner } \\
(1631-35)\end{array}$ & $\begin{array}{c}\text { Provveditore al } \\
\text { cottimo di Londra y } \\
\text { alla Rason vecchie, } \\
\text { Consiglio dei Prega- } \\
\text { di, consigliere delle } \\
\text { leggi; depositario del } \\
\text { banco de giro (cargos } \\
\text { principales) }\end{array}$ & $\begin{array}{l}\text { Saboya y } \\
\text { Madrid }\end{array}$ & $\begin{array}{c}\text { Capitán de Brescia, } \\
\text { consejero de la República, } \\
\text { Riformatore dello studio } \\
\text { di Padova, } 101 .^{\circ} \text { dux de } \\
\text { Venecia }\end{array}$ \\
\hline $\begin{array}{l}\text { Giovanni } \\
\text { Giustinian } \\
(1635-38)\end{array}$ & $\begin{array}{l}\text { Savio agli ordini, } \\
\text { capitán de Vicenza, } \\
\text { podestá y capitán de } \\
\text { Treviso, senador }\end{array}$ & $\begin{array}{l}\text { Madrid, In- } \\
\text { glaterra, Vie- } \\
\text { na y Roma }\end{array}$ & Consejero del dux \\
\hline $\begin{array}{l}\text { Alvise } \\
\text { Contarini } \\
(1638-41)\end{array}$ & $\begin{array}{c}\text { Correttore della } \\
\text { legge, riformato- } \\
\text { re dello studio di } \\
\text { Padova, savio alla } \\
\text { Mercanzia, inquisitore } \\
\text { dell'Armata, savio del } \\
\text { Consiglio }\end{array}$ & $\begin{array}{l}\text { Ámsterdam, } \\
\text { París, Madrid } \\
\text { y Roma }\end{array}$ & $\begin{array}{l}\text { Procuratore di San } \\
\text { Marco, } \\
106 .^{\circ} \text { dux de Venecia }\end{array}$ \\
\hline $\begin{array}{l}\text { Nicolò Sagredo } \\
\quad(1641-44)\end{array}$ & $\begin{array}{c}\text { Savio agli ordini y di } \\
\text { Terraferma }\end{array}$ & $\begin{array}{l}\text { Madrid, Vie- } \\
\text { na y Roma }\end{array}$ & $\begin{array}{l}\text { Savio del Consejo, pro- } \\
\text { curatore di San Marco, } \\
\text { riformatore dello studio } \\
\text { di Padova, } 105 .^{\circ} \text { dux de } \\
\text { Venecia }\end{array}$ \\
\hline $\begin{array}{l}\text { Girolamo } \\
\text { Giustinian } \\
(1644-48)\end{array}$ & Savio agli ordini & $\begin{array}{l}\text { Ámsterdam, } \\
\text { París, Ma- } \\
\text { drid, Viena y } \\
\text { Roma }\end{array}$ & $\begin{array}{l}\text { Savio alla Mercanzia, } \\
\text { Consiglio dei Dieci, } \\
\text { comisario de Vicenza y } \\
\text { provveditore sopra la } \\
\text { Zecca }\end{array}$ \\
\hline $\begin{array}{c}\text { Pietro } \\
\text { Basadonna } \\
(1648-52)\end{array}$ & Savio di terraferma & $\begin{array}{l}\text { Madrid y } \\
\text { Roma }\end{array}$ & $\begin{array}{l}\text { Capitán de Brescia, } \\
\text { consejero de la República, } \\
\text { procuratore di San Mar- } \\
\text { co, cardenal diácono }\end{array}$ \\
\hline
\end{tabular}




\begin{tabular}{|c|c|c|c|}
\hline Embajador & Cargos previos & Embajadas & Promoción posterior \\
\hline $\begin{array}{c}\text { Giacomo } \\
\text { Querini } \\
(1652-56)\end{array}$ & $\begin{array}{c}\text { Savio agli ordini y di } \\
\text { terraferma }\end{array}$ & $\begin{array}{c}\text { Madrid, Roma, } \\
\text { Constantinopla }\end{array}$ & $\begin{array}{c}\text { Savio alle acque, con- } \\
\text { sejero del sestiere de } \\
\text { Dorsoduro, del de Castello } \\
\text { y del Senado }\end{array}$ \\
\hline $\begin{array}{c}\text { Domenico Zane } \\
(1656-58)\end{array}$ & $\begin{array}{c}\text { Savio di terraferma } \\
\text { agli ordini }\end{array}$ & Madrid & Censore \\
\hline $\begin{array}{c}\text { Giorgio Corner } \\
(1661-64)^{36}\end{array}$ & $\begin{array}{c}\text { Savio agli ordini, } \\
\text { di terraferma y alla } \\
\text { scrittura }\end{array}$ & Madrid y Viena & $\begin{array}{c}\text { Provveditore generale en } \\
\text { Dalmacia y Albania }\end{array}$ \\
\hline $\begin{array}{c}\text { Marin Zorzi } \\
(1664-67)\end{array}$ & ------- & Madrid y Viena & Capitán de Padua \\
\hline
\end{tabular}

Avanzando en nuestra argumentación, parece pues plausible determinar que el cargo de savio agli ordini en el Collegio se convirtió en muchos casos en el primer escalafón de una prometedora carrera política en la ciudad de los canales ${ }^{37}$. Allí, en contacto diario con la actividad diplomática de la República, los patricios adquirían unos conocimientos que serían tenidos en cuenta de cara a las nominaciones en el Senado para ocupar una de las embajadas en las distintas cortes. De la misma forma, al igual que la gran mayoría de las magistraturas en Venecia -a excepción de los procuratori di San Marco y el propio dux-, el ejercicio de estos oficios en el Collegio tenía una duración limitada, con vistas a asegurar que todos los miembros

36. Entre 1658 y 1661 la embajada ordinaria de la República permaneció vacante tras la muerte del individuo elegido para ocuparla. Pese a ello, esta ausencia fue cubierta con el envío de un legado extraordinario a finales de 1659, Giacomo Querini, quien regresó a Madrid para felicitar al Rey Católico por el acuerdo de paz con Francia y permaneció en la corte española hasta la llegada de Giorgio Corner. N. BArozzi y G. Berchet (1856), Serie 1, vol. I, 311-312, 324.

37. El Collegio estaba compuesto por diversos tipos de savi: seis savi grandi, los miembros originarios de esta institución creada en torno al año 1400; cinco savi di terraferma, gestores del dominio terrestre de la República; y cinco savi agli ordini, encargados del comercio, la marina y los territorios de ultramar. Junto al dux y a la Signoria estos conformaban el Pien Collegio, que se reunía cada mañana para abordar los asuntos más relevantes. F. C. LANE (1978), 298-300. 
de la oligarquía dominante fueran capaces de acceder a los principales cargos de representación ${ }^{38}$.

Con ello, se pretendía evitar la aparición de facciones dentro de la clase patricia, puesto que estas eran consideradas un signo de debilidad y de falta de compactibilidad entre las grandes casas para con el bienestar de la República ${ }^{39}$. No obstante, lejos de conseguirlo, las facciones nobiliarias y los intereses privados eran inevitables en un cuerpo político conformado por más de 2000 individuos, por lo que resulta harto innegable que estos grupos de poder tuvieron un peso determinante a la hora de iniciar una carrera diplomática ${ }^{40}$.

El caso de Leonardo Moro -embajador en la corte española entre 1624 y 1627 - es probablemente el más representativo al respecto. Sin lugar a duda, de los trece individuos que hemos analizado aquí, Moro era uno de los que más había avanzado en el cursus honorum cuando llegó a la corte española. Tras cumplir los veinticinco años, entre 1601 y 1617 ocupó las magistraturas de savio agli ordini y di Terraferma, provveditore sopra i Conti $y$ alle Pompe, senador, miembro del Pien Collegio, capitán de Bérgamo, sindaco, avogadore e inquisitore di Terraferma ${ }^{41}$. Más todavía, la razón principal que debemos tener en cuenta para entender su rápido ascenso en la pirámide de poder es la cercanía de su padre -Giovanni Moro- a uno de los máximos exponentes de la facción de los giovanni: el procurador de San Marcos Leonardo Mocenigo ${ }^{42}$.

Desde finales del siglo XVI, los patricios que se adscribieron a este grupo clientelar basaron sus postulados en la oposición a la concentración de las principales magistraturas en el Maggior Consiglio y el Senado; así como en la defensa de una política exterior activa en Italia frente a la hegemonía española, en remembranza del pasado glorioso de la República. Frente a ellos se encontraban los denominados vecchi-facción encabezada por los senadores más influyentes en las principales instituciones-, quienes categóricamente defendieron la asunción de una posición neutral a tenor de la disminución de su preponderancia frente al resto de potencias europeas a partir de la derrota sufrida en la batalla de Agnadello (1509) frente a la Liga de Cambrai ${ }^{43}$.

38. D. E. Queller (1986), 44-45.

39. F. C. Lane (1973), 109-110.

40. D. E. Queller (1986), 75-84; F. De Vivo (2007), 40-41.

41. BMV, Cod. It. VII, 17, vol. III, fol. 138r. Campidoglio Veneto..., 1741.

42. V. Mandelli (2012).

43. G. Cozzi, M. Knapton y G. Scarbello (1992), 62-63; S. Andretta (2017), 176-196. 
En cuanto al paso de una embajada a otra, parece pues probado el seguimiento sistemático del cursus honorum que esbozábamos en las primeras páginas de este escrito. Ahora bien, es preciso matizar que la pugna entre las dos grandes monarquías católicas durante estos años provocó la disociación entre ambas sedes a mediados de la centuria. Por ello, tras el paso de Girolamo Giustinian de París a Madrid no observamos que esta situación volviese a repetirse. Probablemente, debido a que este fue recibido con escepticismo a su llegada a la corte española en septiembre de 1644, tras haber ocupado las embajadas en las Provincias Unidas y Francia, ambas en guerra con la Monarquía Católica ${ }^{44}$.

En última instancia, pasamos a abordar su regreso a la Serenísima. Tras leer sus relazioni en el Senado, dos caminos se abrían para los patricios: ser elegidos para regentar una nueva misión diplomática o pasar a ocupar nuevamente importantes oficios de gobierno. Llegados a este punto, nuevamente las relaciones de patronazgo-clientelismo resultaban esenciales para mantenerse en las principales instituciones venecianas ${ }^{45}$.

Este fue el caso de Alvise Corner, quien tras tres años en la corte española regresó a Venecia en 1624. En ese momento, pasó a ocupar un asiento en el Senado que prontamente vio peligrar, ya que el 4 de enero de 1625 su padre era elegido dux de Venecia.

Con vistas a evitar la concentración de poderes en una misma casa, estaba prohibido que los parientes de hasta segundo grado del dogo mantuviesen su derecho a voto (balla) en el cuerpo ejecutivo de la República ${ }^{46}$. No obstante, frente a algunos dogos cuyo papel fue más bien ceremonial, Giovanni I Corner pronto demostró su capacidad para salvaguardar su influencia política y la de sus más allegados ${ }^{47}$. Algo que quedó de manifestó cuando la Signoria aceptó que sus hijos Alvise y Francesco -este último también ocupó la embajada española entre 1631 y 1635- pudiesen tomar

44. ASV, Senato, Dispacci, Spagna, filza 79, fol. 412. Carta de Nicolò Sagredo al Senado, 7 de septiembre de 1644 .

45. Véase al respecto P. F. Brown (1987), 179-212; D. Romano (1993), 712-733.

46. En el Senado, entre 180 y 280 patricios -todos ellos con más de 40 años elegidos en parte por el Maggior Consiglio y en parte ex officio- eran divididos por complejos mecanismos en diferentes grupos con el objetivo de dar orden al proceso de deliberación: algunos votaban y proponían, otros solo votaban o proponían y otros solo acudían a los procedimientos. F. DE VIVO (2007), 28-29.

47. Bouwsma señala que las restricciones del dogo fueron un importante elemento en la concepción política de los venecianos. Su importancia ritual era enorme, mientras que a nivel político dependió de las circunstancias políticas y del carácter del dogo, siendo imposible negar que algunos de estos tuvieron una influencia notable en las instituciones venecianas. W. J. Bouwsma (1968), 61-63. 
parte en los procesos electorales en el Senado. Anomalía que nuevamente se repitió cuando se renovó este organismo a finales de 1625 y en 1626, manteniendo Alvise su derecho a voto en la zonta del Senado. Sin embargo, esta acción tuvo una tajante respuesta por una facción del patriciado capitaneada por Renier Zeno, cuya movilización pretendía poner fin a la acumulación de poder en los miembros de la familia Corner. Protesta que se saldó con la salida de Alvise del Senado en 1627 y una nueva corrección del Consiglio dei Dieci en 1628, con vistas a atajar una crisis que ponía de manifiesto la disparidad entre el mito de Venecia y la realidad en la vida política ${ }^{48}$.

\section{CONCLUSIONES}

La pretendida visión mitificada del sistema político veneciano fue consolidada en el siglo XVI con vistas a soslayar el impacto de la amarga derrota sufrida a manos de la Liga de Cambrai, que marcó el inicio de la decadencia política y comercial de la República de San Marcos hasta su desaparición en 1797.

Hecha esta salvedad, hoy en día resulta imposible negar el peso que tuvieron las luchas políticas entre las diferentes casas nobiliarias. Por ello, aunque la ley veneciana siempre trató de obstaculizar la influencia de las redes informales de poder, es preciso ahondar en las distintas estrategias que estos linajes fueron tejiendo en las distintas salas del Palacio Ducal, centro de la vida política veneciana, para lograr que sus más allegados lograsen acceder a las magistraturas más relevantes. Como no podía ser de otra forma, siempre al calor de la influencia social de la casa y de la capacidad socioeconómica del ramo.

No obstante, ni todos los patricios eran ricos ni todos podían sufragar los dispendiosos gastos de representación. Por esta razón, tal y como advirtió D. E. Queller, la República se encontró con notables dificultades a la hora de encontrar sujetos cualificados para desempeñar los distintos cargos de representación exterior ${ }^{49}$. Fenómeno similar al que se observa en otras potencias europeas, entre ellas la Monarquía Hispánica, siendo especialmente conocida la preocupación del conde-duque de Olivares por la "falta de cabezas" a la hora de encontrar individuos competentes para ocupar los más altos cargos de la administración ${ }^{50}$.

48. C. J. Rose (1974), 479; S. Andretta (2017), 185; C. Povolo (1983).

49. D. E. Queller (1966), 27-28; (1986), 29-34.

50. J. H. Elliot y J. F. de la Peña (1978), vol. II, 162. Citado también en M. Á. OchoA BRUN (2005), 204-206. 
Así mismo, el caso de los embajadores en la corte madrileña permite entrever como la carrera diplomática comenzaba a profesionalizarse con un cursus honorum perfectamente delimitado ${ }^{51}$. Por otro lado, dentro de esta reglamentada carrera política, durante este periodo los embajadores de la Serenísima ante Felipe IV llevaron a cabo una misión vital para la salvaguarda del Stato da Mar veneciano; puesto que la conservación del reino de Candía, rendido finalmente a los otomanos en septiembre de 1669, era vital para conservar cierto lustre político y comercial en el Mediterráneo oriental.

Por ello, los elegidos para regentar esta embajada en muchos casos habían sido o llegaron a ser magistrados relevantes en la vida política veneciana. Hasta el punto de que tres de ellos llegaron a alcanzar incluso la dignidad ducal. Más aún, muchos de ellos no volvieron a ocupar otra embajada, prefiriendo regentar los oficios más relevantes en la política interna de la ciudad lagunar, mucho más ventajosos para sus intereses políticos y económicos más inmediatos. Sin embargo, la experiencia diplomática era un peldaño fundamental en la escalera de poder debido al valioso conocimiento en política exterior que otorgaba. Por ello, conviene subrayar que la embajada española era precisamente uno de los enclaves más eficaces para ganar dicha experiencia.

\section{BIBLIOGRAFÍA}

Alonge, Guillaume (2019), Ambasciatori. Diplomazia e politica nella Venezia del Rinascimento, Donzelli, Roma.

ANDRETTA, Stefano (1978), La diplomazia veneziana e la pace di Vestfalia (16431648), Annuario dell'istituto storico italiano per l'età moderna e contemporanea, Roma.

- (2000), La Repubblica inquieta. Venezia nel Seicento tra Italia ed Europa, Carocci, Roma.

- (2008), "Relaciones con Venecia", en J. Martínez Millán y M. a A. Visceglia (dirs.), La monarquía de Felipe III, Fundación Mapfre, Madrid, vol. IV, pp. 1075-1092.

- (2010), "Forme della comunicazione diplomatica in un contesto di crisi: gli ambasciatori veneziani durante la Fronda parlamentare a Parigi (1648-49)", en S. Andretta et alii (eds.), Paroles de négociateurs: L'entretien dans la pratique diplomatique de la fin du Moyen Age à la fin du XIXe siècle, École française de Rome, Roma, pp. 193-211.

51. D. RAInes (2016), vol. I, 274-275. 
- (2017), "Giovani and vecchi: the factionary spirit in $16^{\text {th }}$ and $17^{\text {th }}$ centuries patrician Venice between myth and reality”, en R. GonzÁlez Cuerva y A. Koller (eds.), A Europe of courts, a Europe of factions. Political groups at Early Modern centres of power (1550-1700), Brill, Leiden, pp. 176-196.

BAROzzi, Nicolo y BerChet, Guglielmo (1856), Relazioni degli stati europei lette al Senato dagli ambasciatori veneti nel secolo decimosettimo, Serie I: Spagna, vol. I, P. Naratovich, Venecia.

Benzoni, Gino (1988), "Venezia e la Spagna nel Seicento”, en Venezia e la Spagna, Banca Cattolica, Milán, pp. 155-178.

BéLy, Lucien (2009), Turcs et turqueries (XVIe-XVIIIe siècles), Presses de l’Université Paris-Sorbonne, París.

Benzoni, Gino (1990), “Ranke's Favourite Source: The Venetian Relazioni, Impression with Allusions to Later Historiography", en G. G. IGGERs y J. M. Powell (eds.), Leopold von Ranke and the shaping of the historical discipline, Syracuse University Press, Siracusa (Nueva York), pp. 45-58.

Besta, Enrico (1899), Il senato veneziano (origine, costituzione, attribuzioni e riti), La Società, Venecia.

Bouwsma, William J. (1968), Venice and the Defense of Republican Liberty. Renaissance Values in the Age of the Counter Reformation, University of California Press, Berkeley-Los Ángeles.

Brown, Patricia F. (1987), "Honour and Necessity: The Dynamics of Patronage in the Confraternities of Renaissance Venice”, Studi Veneziani, 14, pp. 179-212.

Bunes Ibarra, Miguel Ángel de (2001), “Carlos V, Venecia y la Sublime Puerta la embajada de Diego Hurtado de Mendoza en Venecia”, en J. Martínez Millán e I. J. EzQuerra Revilla (coords.), Carlos $V$ y la quiebra del humanismo político en Europa (1530-1558), vol. I, Sociedad Estatal para la Conmemoración de los Centenarios de Felipe II y Carlos V, Madrid, pp. 591-618.

Campana, Carlo (2001), "Les ambassadeurs de Venise, acteurs et sources de l'Histoire", en M. VAILlON-SChONEveld (ed.), L'histoire et les historiens au XVIe siècle, Université, Saint-Étienne, pp. 43-58.

Canali, Pierluigi y Curti, Laura (1988), "Nascita, matrimoni, cursus honorum nel patriziato veneziano", Mélanges de l'École française de Rome, 100, pp. 137-146.

CARrió-Invernizzi, Diana (2013), "Diplomacia informal y cultura de las apariencias en al Italia española”, en C. Bravo Lozano y R. Quirós Rosado (eds.), En tierra de confluencias. Italia y la Monarquía de España siglos XVI-XVIII, Albatros Ediciones, Madrid, pp. 99-110.

- (2014), "A New Diplomatic History and the Networks of Spanish Diplomacy in the Baroque Era", The International History Review, 36/4, pp. 603-618.

- (2016), “Introducción”, en D. CARrió-InvERnizzi (dir.), Embajadores culturales. Transferencias y lealtades de la diplomacia española de la Edad Moderna, Universidad Nacional de Educación a Distancia, Madrid, pp. 17- 34. 
Cozzi, Gaetano; Knapton, Michael; Scarbello, Giovanni (1992), “La Repubblica di Venezia nell'età moderna. Dal 1517 alla fine della Repubblica”, en G. Galasso (dir.), Storia d'Italia, vol. XII, t. II, UTET, Turín.

Crouzet-Pavan, Elisabeth (1999), Venise triomphante. Les horizons d'un mythe, Albin Michel, París.

Descendre, Romain (2007), “Analyse géopolitique et diplomatie au XVIe siècle. La qualification de l'ennemi dans les relazioni des ambassadeurs vénitiens", Astérion, 5. URL: http://journals.openedition.org/asterion/724 (consulta: 5-11-2019).

Dizionario Biografico degli Italiani, Istituto dell'Enciclopedia italiana, Roma, 1960-presente. URL: http://www.treccani.it/biografie/

Dursteler, Eric D. (2011), "Describing or distorting the turk?: the Relazioni of the venetian ambassadors in Constantinople as Historical Source", Acta Histriae 19, pp. 231-248.

Fasoli, Gina (1958a), La Storia di Venezia, Editrice R. Patrón, Bolonia.

- (1958b), "Nascita di un mito", en VV. AA., Studi storici in onore di Gioacchino Volpe, vol. I, G.C. Sansoni, Florencia, pp. 445-479.

Dient, Charles (1967), La république de Venise, Flammarion, París.

Elliot, John H. y Peña, José F. de la (1978), Memoriales y cartas del Conde Duque de Olivares, Alfaguara, Madrid.

Gaeta, Franco (1961), "Alcune considerazioni sul mito di Venezia", Bibliothèque d'Humanisme et Renaissance, 23, pp. 58-75.

Gilmore, Myron P. (1973), "Myth and Reality in Venetian political theory", en J. R. Hale (dir.), Renaissance Venice, Rowman \& Littlefield, Londres, pp. 431-444.

González Cuerva, Rubén (2012), Baltasar de Zúñiga. Una encrucijada de la Monarquía Hispana (1561-1622), Polifemo, Madrid.

Haitsma Mulier, Eco O. G. (1980), The myth of Venice and the Dutch Republican Thought in the Seventeenth Century, Van Gorcum, Assen.

Hunecke, Volker (1997) Il patriziato veneziano alla fine della Repubblica, 16461797. Demografia, famiglia, ménage, Jouvence, Roma.

Lane, Frederic C (1973), Venice. A maritime republic, The Johns Hopkins University Press, Baltimore.

- (1978), Storia di Venezia, G. Einaudi, Turín.

Levin, Michael J. (2005), Agents of Empire: Spanish Ambassadors in Sixteenthcentury Italy, Cornell University Press, Ítaca (Nueva York) y Londres.

Mandelli, Vittorio (2012), "Leonardo Moro", en Dizionario Biografico degli Italiani, vol. 77, Istituto dell'Enciclopedia italiana, Roma. URL: http://www. treccani.it/enciclopedia/leonardo-moro_\%28Dizionario-Biografico\%29/ (consulta: 5-11-2019).

MARÉCHAUX, Benoît (2012), "Negociar, disuadir y comunicar para la conservación y reputación de la Monarquía: la república de Venecia en las estrategias de la Pax Hispánica bajo el valimiento de Lerma", en B. García García, M. 
Herrero Sánchez y A. Hugon (dirs.), El arte de la prudencia. La Tregua de los Doce Años en la Europa de los Pacificadores, Fundación Carlos de Amberes, Madrid, pp. 91-120.

Martínez Millán, José (1996), "Las investigaciones sobre patronazgo y clientelismo en la administración", Studia Historica. Historia Moderna, 15, pp. 83-106.

Miranda Rubio, Francisco (1994), "La nueva historia política", Estudios de ciencias sociales, 7, pp. 199-212.

Mosto, Andrea da (1937), L'Archivio di Stato di Venezia. Indice generale, storico, descrittivo ed analitico, t. I, Biblioteca d'Arte Editrice, Roma.

Muir, Edward (1987), Civil ritual in Renaissance Venice, Princeton University Press, Princeton.

Negredo del Cerro, Fernando (2016), La guerra de los Treinta Años. Una visión desde la Monarquía Hispánica, Síntesis, Madrid.

Ochoa Brun, Miguel Ángel (2005), "Los embajadores de Felipe IV", en J. ALCAlÁ-Zamora y Queipo de Llano, Felipe IV: el hombre y el reinado, Real Academia de la Historia, Madrid, pp. 199-234.

PAntalacci, Jean-Pierre (2009), "Le personnel diplomatique vénitien à travers l'Europe, dans la première moitié du XVI' siècle", Cahiers de la Méditerranée, 78/II, pp. 263-277.

Petitjean, Johann (2013), L'intelligence des choses: une histoire de l'information entre Italie et Méditerranée (XVIe-XVIIe siècles), École française de Rome, Roma.

Povolo, Claudio (1983), “Alvise Corner”, en Dizionario Biografico degli Italia$n i$, vol. 29, Istituto dell'Enciclopedia italiana, Roma. URL: http:/www. treccani.it/enciclopedia/alvise-corner_res-43781650-87eb-11dc-8e9d0016357eee51_\%28Dizionario-Biografico\%29/ (consulta: 5-11-2019).

Poumarède, Géraud (2000), "La question d'Orient au temps de Westphalie", en L. BÉLY (coord.), L'Europe des traites de Westphalie, Esprit de la diplomatie et diplomatie de l'esprit, Presses Universitaires de France, París, pp. 363-390.

Preto, Paolo (1994), I servizi segreti di Venezia. Spionaggio e controspionaggio ai tempi della Serenissima, Il Saggiatore, Milán.

Queller, Donald E. (1966), Early Venetian Legislation on Ambassador, Droz, Génova.

- (1967), The Office of the Ambassador in the Middle Ages, Princeton University Press, Princeton.

- (1973), “The development of Ambassadorial Relazioni”, en J. R. HALE (dir.) Renaissance Venice, Faber and Faber, Londres.

- (1986), The venetian patriciate. Reality versus Myth, University of Illinois Press, Urbana y Chicago.

Quiles Albero, David (2019), “La guerra de Candía (1645-1669): ¿Causa común en una Europa dividida?", Tiempos Modernos, 38, pp. 176-195.

RAINES, Dorit (1991), "Pouvoir ou privilèges nobiliaires. Le dilemme du patriciat vénitien face aux agrégations du XVII siècle", Annales. Économies, Sociétés, Civilisations, 46/4, pp. 827-847. 
- (2003), “Cooptazione, aggregazione e presenza al Maggior Consiglio: le casate del patriziato veneziano, 1297-1797”, Storia di Venezia, 1, pp. 1-64.

- (2006), "Strategie d'ascesa sociale e giochi di potere a Venezia nel Seicento: le aggregazioni alla nobiltà", Studi Veneziani, 56, pp. 279-317.

- (2016), L'invention du mythe Aristocratique. L'image de soi du patriciat vénitien au temps de la Sérénissime, 2 vols., Istituto Veneto di Scienze, Lettere ed Arti Venecia.

Rivero Rodríguez, Manuel (2000), Diplomacia y relaciones exteriores en la Edad Moderna. De la Cristiandad al sistema europeo, 1453-1794, Alianza, Madrid.

- (2018), "Diplomacia, dinastía y confesión: La guerra de los Treinta Años y el nacimiento de la política exterior en la Europa moderna", Vínculos de Historia, 7, pp. 61-78.

Rodríguez Salgado, María José (2004), Felipe II, el "paladín de la Cristiandad" y la paz con el turco, Universidad, Valladolid.

Romano, Dennis (1993), "Aspects of Patronage in Fifteenth- and Sixteenth-Century Venice”, Renaissance Quarterly, 46/4, pp. 712-733.

Rösch, Gerhard (2000), "The Serrata of the Great Council and the Venetian Society, 1286-1323”, en J. J. Martin y D. Romano (eds.), Venice Reconsidered. The History and Civilization of an Italian City-State, 1297-1797, The Johns Hopkins University Press, Baltimore y Londres, pp. 67-88.

Rose, Charles J. (1974), "Marc Antonio Venier, Renier Zeno and The Myth of Venice", The Historian, 36/3, pp. 479-497.

Setton, Keneth M. (1991), Venice, Austria and the Turks in the Seventeenth century, The American Philosophical Society, Filadelfia.

Stone, Lawrence (1982), "Prosopografía", en El pasado y el Presente, Fondo de Cultura Económica, México D. F.

Thiriet, Freddy (1952), Histoire de Venise, Presses Universitaires de France, París.

Trampus, Antonio (2010), "Le diplomatie vénitien entre les XVI" et XVIII" siècles: statut, rôles et fonctions", Études de Lettres, 3, pp. 119-136.

TÜRKÇELIK, Evrim (2015), "El Imperio otomano y la política de alianzas: las relaciones franco-otomanas en el tránsito del siglo XVI al XVII”, Hispania, 75, pp. 39-68.

Ventura, Angelo (1976), Relazioni degli ambasciatori veneto al Senato, Laterza, Bari.

VIVo, Filippo de (2007), Information and communication in Venice. Rethinking Early Modern Politics, Oxford University Press.

- (2011), "How to Read Venetian Relazioni", Renaissance et Réforme, 34, pp. 25-59.

- (2012), Patrizi, informatori, Barbieri. Politica e comunicazione a Venezia nella prima età moderna, Feltrineli, Milán.

Volpi, Giuseppe (1928), La Repubblica di Venezia e i suoi Ambasciatori, A. Mondadori, Milán.

ZANNINI, Andrea (2010), "Economic and social aspects of the crisis of venetian diplomacy in the seventeenth and eighteenth centuries", en D. Frigo (ed.), Politics and Diplomacy in Early Modern Italy: the structure of diplomatic practice 1450-1800, Cambridge University Press, pp. 109-146. 